\title{
The role of cross sectional echocardiography and pulsed Doppler ultrasound in the management of neonates in whom congenital heart disease is
} suspected

\section{A prospective study}

\author{
MAURICE P LEUNG, C K MOK, K K LAU, ROXY LO, C Y YEUNG \\ From the Department of Paediatrics and Surgery, ${ }^{\star}$ University of Hong Kong, Grantham Hospital, \\ Hong Kong
}

SUMMARY The application of cross sectional echocardiography and pulsed Doppler ultrasound to the management of symptomatic neonates with suspected congenital heart disease was studied in 96 consecutive cases. The ability of echocardiography to establish a complete and accurate diagnosis and a correct management plan was evaluated. Sequential segmental analysis of data from cardiac catheterisation and necropsy identified 536 cardiovascular anomalies. Of the 536 anomalies 512 were correctly diagnosed by echocardiography (sensitivity $95.5 \%$ ). Seven false positive echocardiographic diagnoses were made (specificity $98.6 \%$ ). Nearly all the missing diagnoses and all the false positive diagnoses made by echocardiography were extracardiac vascular anomalies. Normal cardiovascular anatomy was at all times correctly identified by echocardiography. In 12 babies $(12.5 \%$ ) a management plan could not be established because of inconclusive echocardiographic findings. Of the 84 proposed plans based on the echocardiographic findings, eight were found to be inappropriate after catheterisation. Thus, 76 babies $(79 \cdot 2 \%)$ could have been correctly managed without cardiac catheterisation. The combination of cross sectional echocardiography and pulsed Doppler ultrasound not only allows diagnosis of congenital cardiac anomalies in most neonates but can facilitate appropriate clinical management. Only a minority of neonates with suspected congenital heart disease require cardiac catheterisation and angiography.

Mortality is high in infants who present with cardiorespiratory symptoms in the first few weeks of life. ${ }^{12}$ Appropriate lifesaving management including early operation depends on the accurate determination of the cardiovascular anatomy and haemodynamic function. Although conventional cardiac catheterisation and cinecardioangiography are valuable diagnostic methods, they are not without hazards especially when performed on the critically ill neonates. ${ }^{3}$ High resolution cross sectional echocardiography can define intracardiac, ${ }^{45}$ great artery, ${ }^{67}$ systemic venous ${ }^{8}$ and pulmonary venous ${ }^{9}$

Requests for reprints to Dr Maurice P Leung, Department of Paediatrics, The Grantham Hospital, 125 Wong Chuk Hang Road, Hong Kong.

Accepted for publication 29 January 1986 anomalies and relations, while pulsed Doppler ultrasound can detect and quantify intracardiac ${ }^{10}$ and extracardiac ${ }^{11}$ shunts, valvar stenosis, ${ }^{1213}$ and valvar regurgitation. ${ }^{14} 15$

Since cross sectional echocardiography and pulsed Doppler ultrasound are non-invasive and complication-free procedures, they are attractive alternatives to the conventional invasive diagnostic methods. We assessed the role of combined cross sectional echocardiography and pulsed Doppler ultrasound in the management of symptomatic neonates in whom congenital heart disease is suspected.

\section{Patients and methods}

We studied 96 consecutive neonates (mean age 11 
days) admitted to the Grantham Hospital with cardiorespiratory symptoms (heart failure, cyanosis, and tachypnoea) between October 1983 and April 1985. To evaluate the role of echocardiography in the management of these neonates, we determined its ability to establish a complete and accurate diagnosis and a correct management plan. On admission careful clinical assessment, chest radiograph, standard electrocardiogram, and laboratory tests were carried out.

Cross sectional echocardiography and pulsed Doppler ultrasound were then performed by one of the three paediatric cardiologists (MPL, KCL, RL) using an Advanced Technology Laboratory (mark V series 300) mechanical scanner fitted with a 5 or $7.5 \mathrm{MHz}$ transducer. The atrial situs, ${ }^{16}$ atrioventricular and ventriculoarterial junctions were defined and ventricular morphology and intracardiac anatomy were studied in the standard views. ${ }^{17} \mathrm{~A}$ search was made for extracardiac vascular anomalies, intracardiac and extracardiac shunts, valvar stenosis, and regurgitation. All echocardiograms were recorded on video tapes and were reviewed by all three paediatric cardiologists together. The clinical history, results of the physical examination, electrocardiograms, and chest radiographs were available to all physicians.

Depending on the clinical and echocardiographic findings either medical or surgical management was proposed whenever possible. If operation was indicated it was planned together with the surgeon (CKM). Cardiac catheterisation was then carried out according to the indications recommended by Rudolph ${ }^{18}$ except in those who were moribund on admission. Catheterisation was performed under general anaesthesia with intermittent positive pressure ventilation. Conventional techniques were used. The approach and pattern of study adopted were that appropriate to each individual patient's condition and pre-catheterisation diagnosis.

The aim of all studies was to achieve a complete diagnosis in the shortest possible time. After cardiac catheterisation a definitive management plan was made and executed. Neonates with normal cardiovascular anatomy (for example, those with isolated persistent fetal circulation), cardiovascular anomalies without critical haemodynamic derangement (for example, tetralogy of Fallot without severe hypoxaemia), uncorrectable cardiovascular anomalies (for example, aortic atresia), and those who were moribund were managed conservatively. The remaining neonates who had operable cardiovascular anomalies with critical derangement of haemodynamic function (for example, pulmonary atresia, total anomalous pulmonary venous connection) were subjected to either palliative or cor- rective surgery, and balloon septostomy was performed in babies with transposition of great arteries.

The echocardiographic findings were compared with the catheterisation or necropsy findings. We used the sequential segmental approach ${ }^{19}$ to determine the sensitivity and specificity of echocardiography in determining cardiac anatomy:

\section{Sensitivity $=$}

number of correct echocardiographic diagnoses

number of catheterisation + necropsy diagnoses

Specificity $=$

number of correct echocardiographic diagnoses

number of correct + false positive echocardiographic diagnoses

If an echocardiographic diagnosis was in doubt and if it was later confirmed by cardiac catheterisation, it was not counted as a correct diagnosis. If, however, a doubtful echocardiographic diagnosis was later disproved by cardiac catheterisation, it was regarded as a false positive diagnosis.

The impact of echocardiography on the management of these babies was evaluated by comparing the proposed management plan based on echocardiographic findings with the definitive management.

\section{Results}

Cross sectional echocardiography and pulsed Doppler ultrasound were satisfactorily performed and recorded on all neonates. Cardiac catheterisation was carried out in all babies except seven who were moribund on admission. At catheterisation five babies had transient arrhythmia during manipulation of the catheter. In 10 babies the body temperature fell below $35^{\circ} \mathrm{C} ; 12$ babies developed metabolic acidosis requiring correction and one baby died. Two babies later developed acute renal failure and a total of 35 babies received blood transfusion. All seven babies who were moribund and not catheterised died soon after admission and in all of them a necropsy was performed. Five had hypoplastic left heart syndrome, one each with interrupted aorta associated with truncus arteriosus and coarctation of aorta associated with aortic stenosis.

\section{DIAGNOSIS}

In four babies no structural cardiac abnormality was found by either echocardiography or cardiac cath- $\stackrel{\mathscr{Q}}{?}$ eterisation. In all four babies the fetal pattern of high 0 pulmonary vascular resistance persisted. Table 1 lists the congenital cardiovascular anomalies found in 92 babies.

A total of 536 cardiovascular anomalies were diagnosed by sequential segmental analysis of data 
Table 1 Diagnostic classification

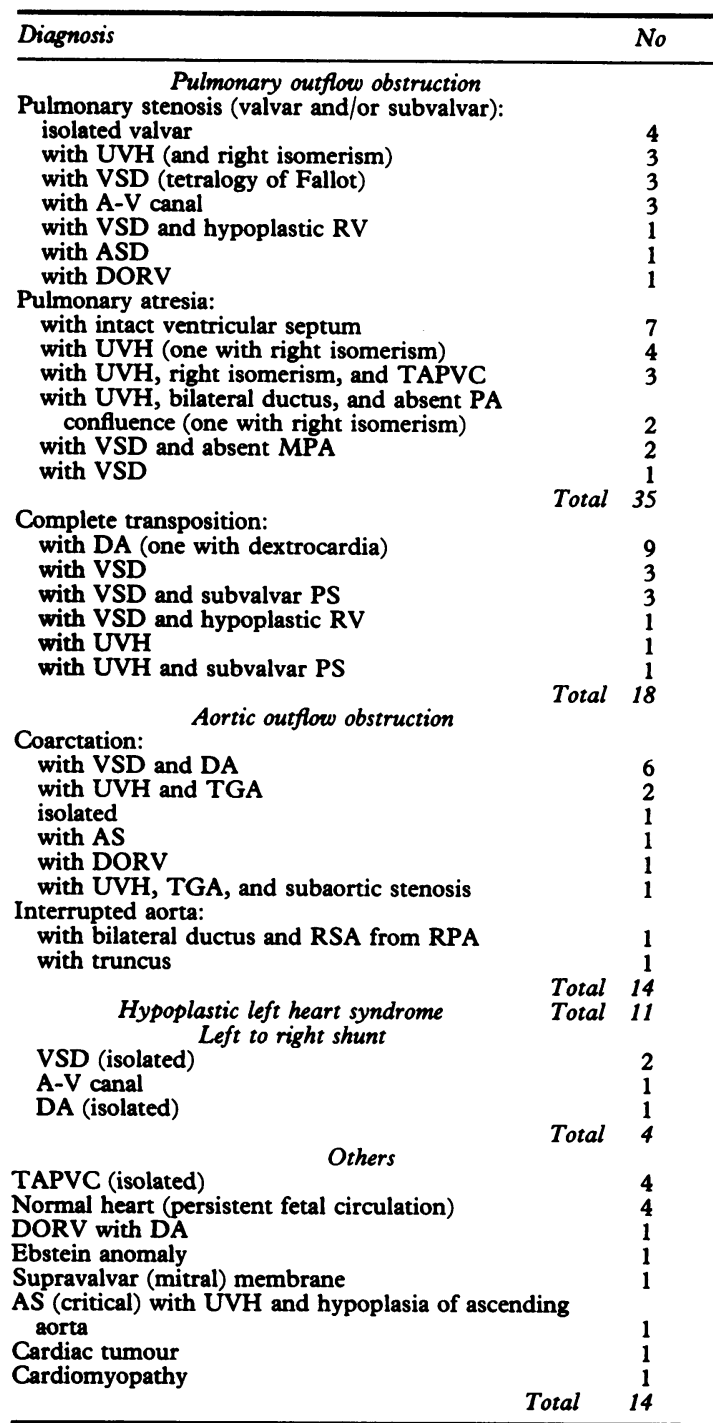

AS, aortic stenosis; ASD, atrial septal defect; A-V, atrioventricular; DORV, double outlet right ventricle; MPA, main pulmonary artery; PA, pulmonary artery; DA, ductus arteriosus; PS, pulmonary stenosis; RSA, right subclavian artery; RPA, right pulmonary artery; RV, right ventricle; TAPVC, total anomalous pulmonary venous confluence; TGA, transposition of great arteries; UVH, heart with univentricular atrioventricular connection; VSD, ventricular septal defect.

obtained at cardiac catheterisation and at necropsy. Of these, 512 were correctly identified by echocardiography, yielding a sensitivity of $95.5 \%$. Seven false positive diagnoses were made by echocardiography, so the specificity of the technique was $98.6 \%$. The normal cardiac segments were correctly identified by echocardiography. Table 2 summarises the segmental analysis.
One case of suspected ventricular septal defect was confirmed and one case of suspected ductus arteriosus was excluded by catheterisation. Of the three cases of suspected coarctation of aorta, two were confirmed and one was excluded by catheterisation. In seven babies with right isomerism and compromised pulmonary blood flow, the pulmonary venous connection could only be defined by catheterisation, and obstructed total anomalous pulmonary venous connection was demonstrated in three babies. Echocardiography failed to diagnose one of the eight cases of right isomerism, two cases each of aberrant right subclavian artery and absent main pulmonary artery, three cases of bilateral ductus arteriosus, and six of ductus arteriosus. Among these 14 babies with missed diagnoses, 13 had other associated anomalies that were identified by echocardiography. In two cases of isolated total anomalous pulmonary venous connection, the drainage site of the common pulmonary venous trunk could only be determined by catheterisation. Two of the seven babies with pulmonary atresia and intact ventricular septum had extensive myocardial sinusoid-coronary communications and these were demonstrated by angiography only.

In the present study, pulsed Doppler ultrasound was found to be a useful adjunct in diagnosing extracardiac vascular anomalies and abnormal valvar function. It was extremely helpful in the detection of ductus arteriosus, coarctation of aorta, abnormal systemic venous channels, and valvar regurgitation. In two cases of total anomalous pulmonary venous connection the drainage site of the common pulmonary venous trunk could not be located without pulsed Doppler ultrasound. It overestimated the severity of one case of pulmonary stenosis, however, and was of limited value in defining the pulmonary venous connection in babies with right isomerism and compromised pulmonary blood flow.

\section{PROPOSED AND DEFINITIVE MANAGEMENT} PLANS

The management of $12(12.5 \%)$ babies could not be planned on the basis of clinical and echocardiographic findings alone. As mentioned above, seven babies with right isomerism and compromised pulmonary blood flow required catheterisation to define their pulmonary venous connection. Obstructed total anomalous pulmonary venous connection was diagnosed in three and this precluded systemicto-pulmonary artery shunting. Two patients with isolated total anomalous pulmonary venous connection required catheterisation to determine the drainage site of the common pulmonary venous trunk before operation. Two of three cases of suspected coarctation of aorta were confirmed by angio- 
Table 2 Comparison of cross sectional echocardiography and cardiac catheterisation and necropsy findings in diagnosing cardiac anomalies

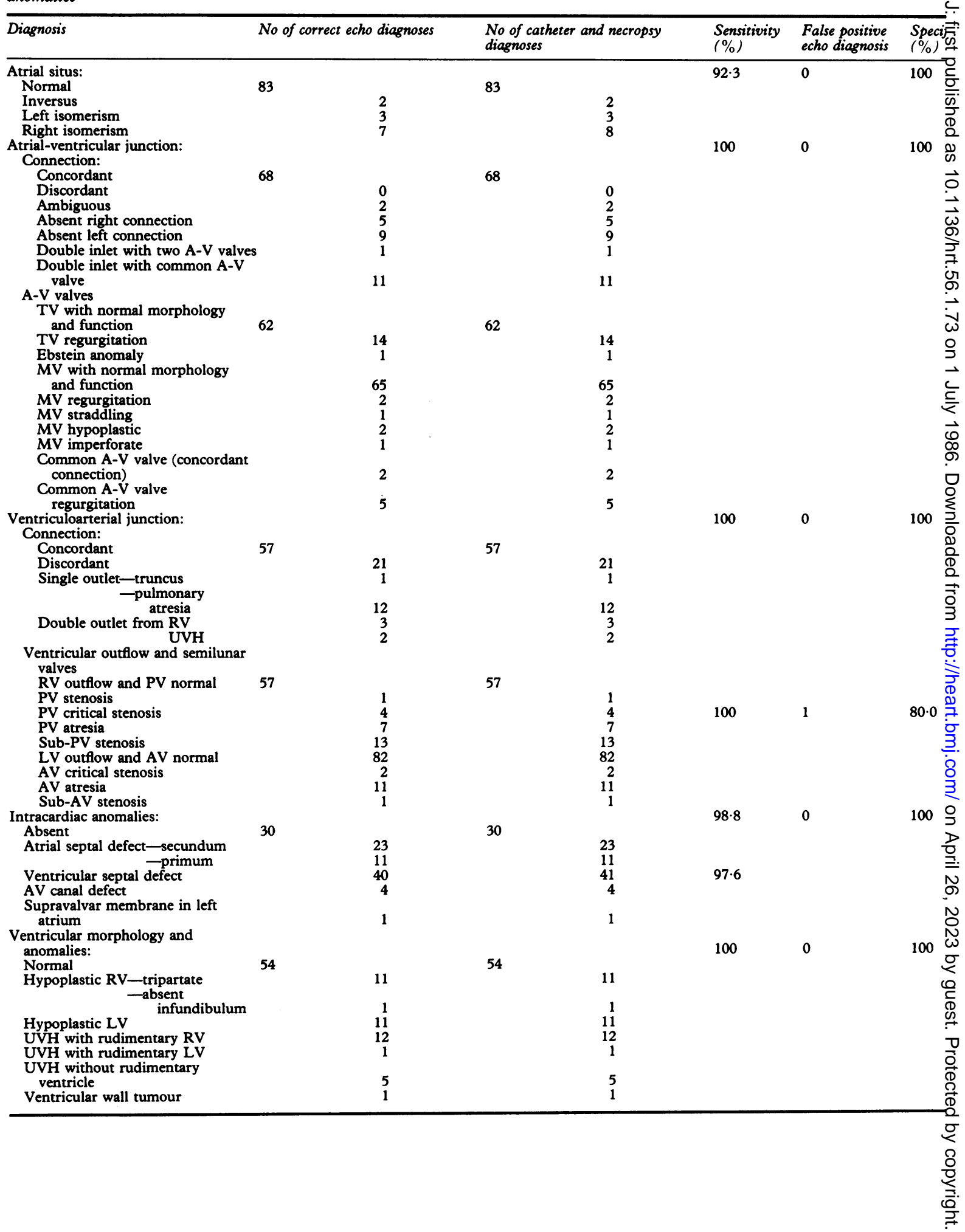


sle 2-continued

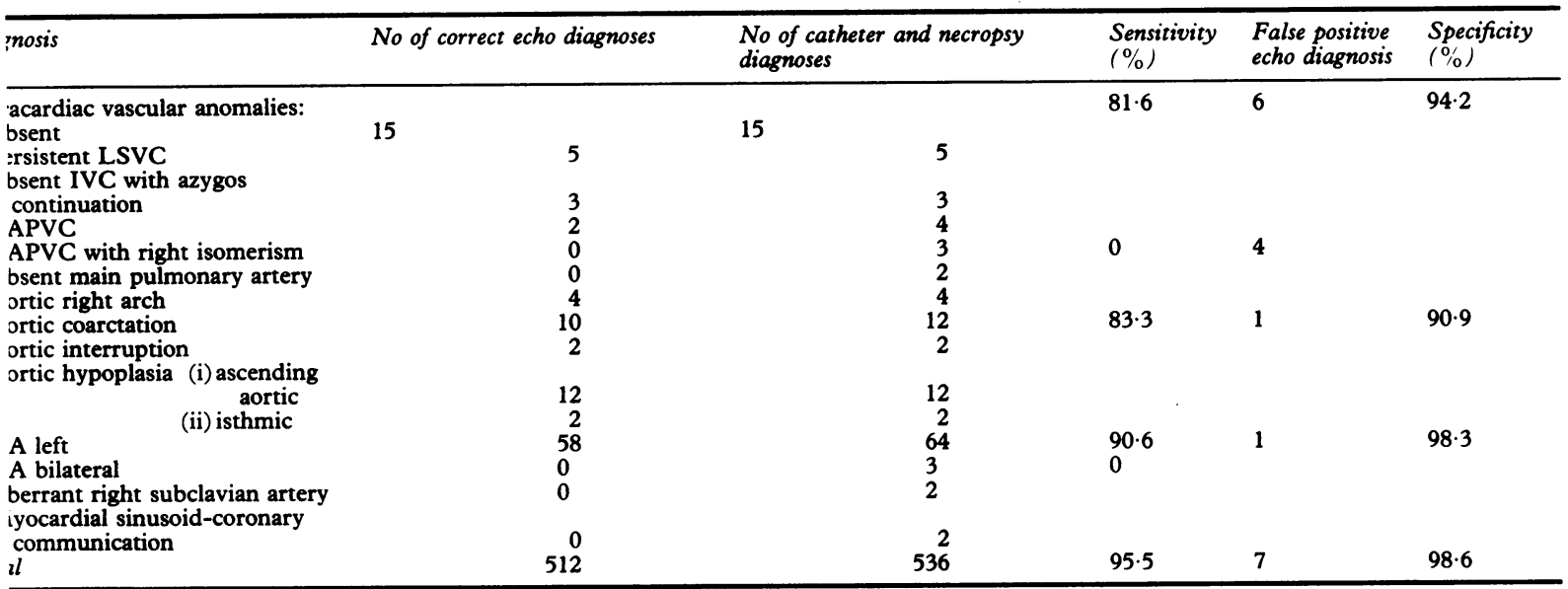

atrioventricular; AV, aortic valve IVC, inferior vena cava; $L S V C$, left superior vena cava; $L V$, left ventricle; $M V$, mitral valve; DA, ductus arteriosus; pulmonary valve; RV, right ventricle; TAPVC, total anomalous pulmonary venous confluence; TV, tricuspid valve; UVH, heart with univentricular ventricular connection.
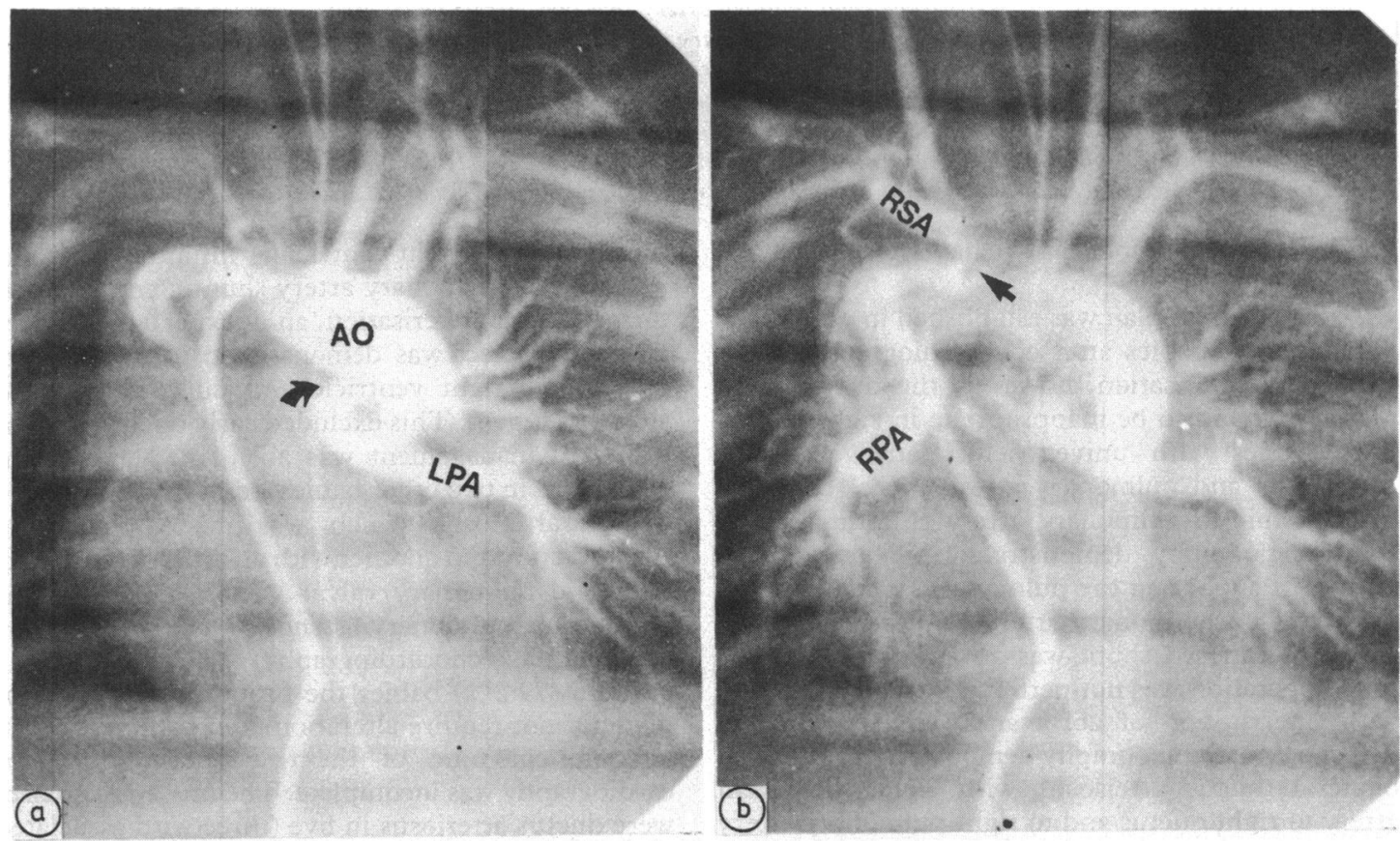

Fig. 1 (a) Aortogram showing a left sided ductius (curved black arrow) feeding into the left pulmonary artery only. (b) Another frame from the same aortogram showing a right sided ductus (straight black arrow) arising from the right subclavian artery and feeding into the right pulmonary artery. There was no confluence between the left and right pulmonary arteries. Cross sectional echocardiography failed to identify these tortuous anomalous vessels. AO, aorta; LPA, left pulmonary artery; $R P A$, right pulmonary artery. 

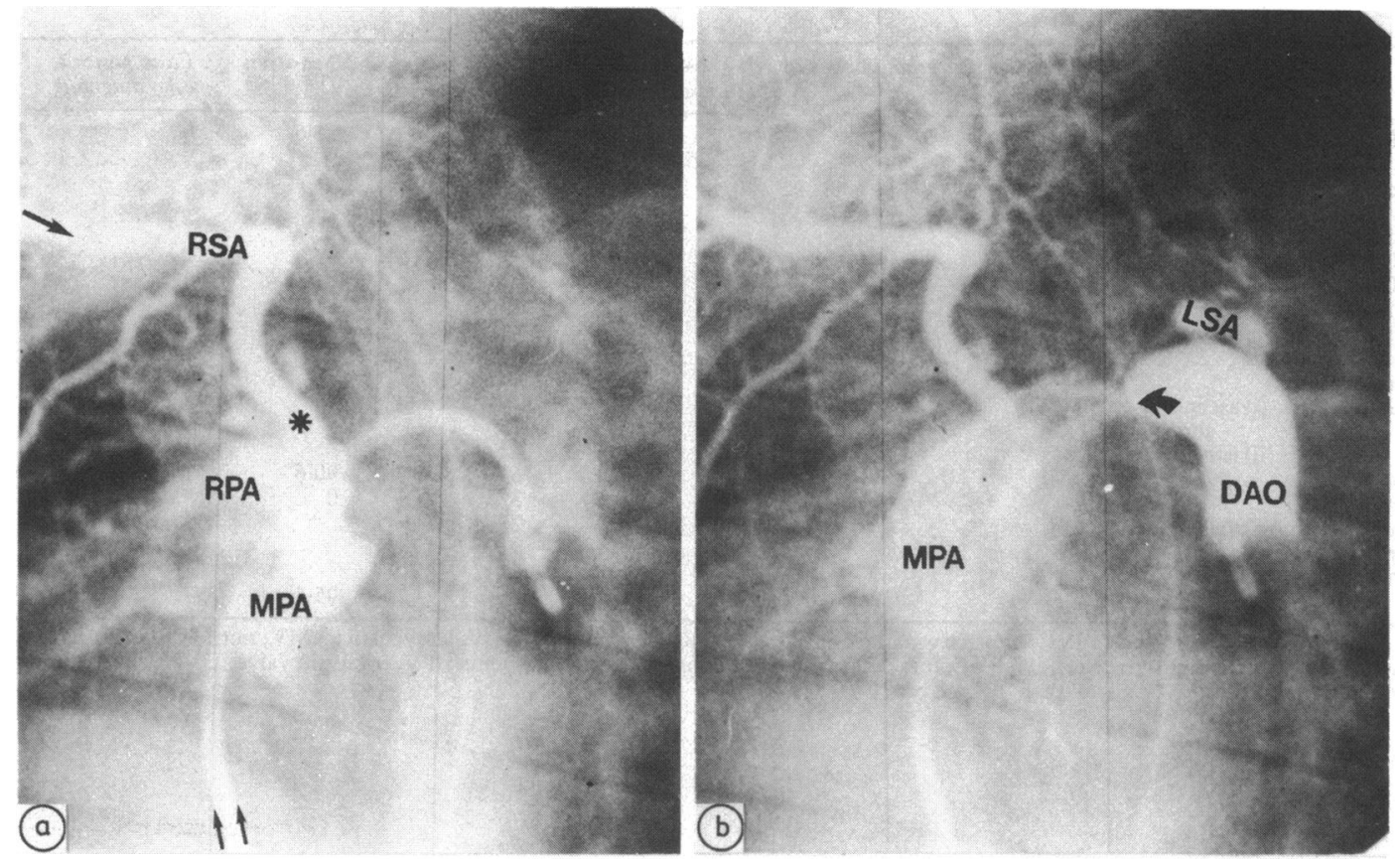

Fig. 2 Angiography by double catheter technique showing the complex anatomy of interruption of aorta and bilateral ductus arteriosus. (a) Retrograde right axillary artery injection (single black arrow) showed up the right subclavian artery-right ductus (black star)-right pulmonary artery continuation. The second balloon catheter (double black arrows) traversed the main pulmonary artery and descending aorta through a large left ductus. (b) Separate injection through the balloon catheter outlined the main pulmonary artery-left ductus (curved black arrow)-descending aorta continuation and the left subclavian artery arising from the descending aorta. Cross sectional echocardiography failed to demonstrate the right sided ductus. DAO, descending aorta, LSA, left subclavian artery; MPA, main pulmonary artery; $R P A$, right pulmonary artery; $R S A$, right subclavian artery.

graphy; the remaining patient had isolated cardiomyopathy.

A management plan was established in each of the remaining 84 babies after echocardiography. After cardiac catheterisation, however, the management plan was found to be inappropriate in eight babies. Two babies with univentricular atrioventricular connection and pulmonary atresia were scheduled for systemic-to-pulmonary artery shunting. However, angiography demonstrated bilateral ductus arteriosus supplying the pulmonary circulation and there was no pulmonary artery confluence (Fig. 1), and the proposed shunt was abandoned. The proposed operation was not performed in another baby with interruption of aorta and ventricular septal defect because angiography demonstrated additional bilateral ductus arteriosus with right subclavian artery to right ductus and to right pulmonary artery continuation (Fig. 2). Two babies with pulmonary atresia and intact ventricular septum were scheduled for closed transventricular pulmonary valvotomy, but this was ruled out by the angiographic demonstration of extensive sinusoidal coronary commu- nications at the right ventricular infundibulum, and systemic-to-pulmonary artery shunt alone was performed. At catheterisation, an unexpected ventricular septal defect was demonstrated in a baby with hypoplastic right ventricle and pulmonary valvar stenosis (Fig. 3). This excluded early operation. The proposed management was abandoned after catheterisation in two other babies-one with an isolated ductus arteriosus which was missed by echocardiography and another with an atrial septal defect and mild pulmonary valvar stenosis in whom the degree of pulmonary stenosis had been overestimated by echocardiography.

In $76(79.2 \%)$ babies the proposed management plan did not require alteration after catheterisation, although in nine of them diagnosis by echocardiography was incomplete. The missed diagnoses were ductus arteriosus in five (three with associated transposition of the great arteries, one with associated coarctation of aorta and ventricular septal defect, and the remaining one with infradiaphragmatic total anomalous pulmonary venous connection), aberrant right subclavian artery in two 

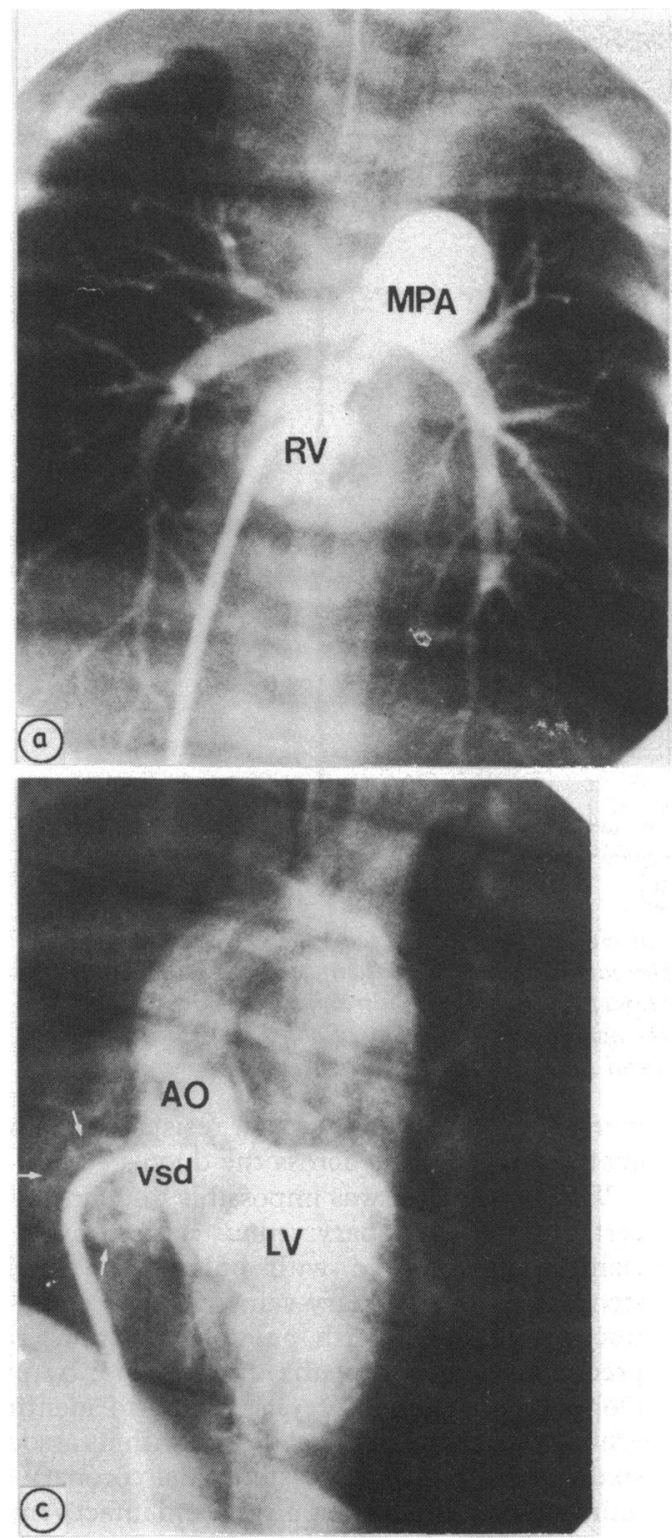

babies (one had associated hypoplastic left heart syndrome and the other had associated coarctation of aorta, ductus arteriosus, and ventricular septal defect), and absent main pulmonary artery in two other babies with pulmonary atresia and ventricular septal defect. Thus, echocardiography provided complete diagnosis in $67(69 \cdot 8 \%)$ babies.

\section{Discussion}

To keep echocardiography as a totally non-invasive

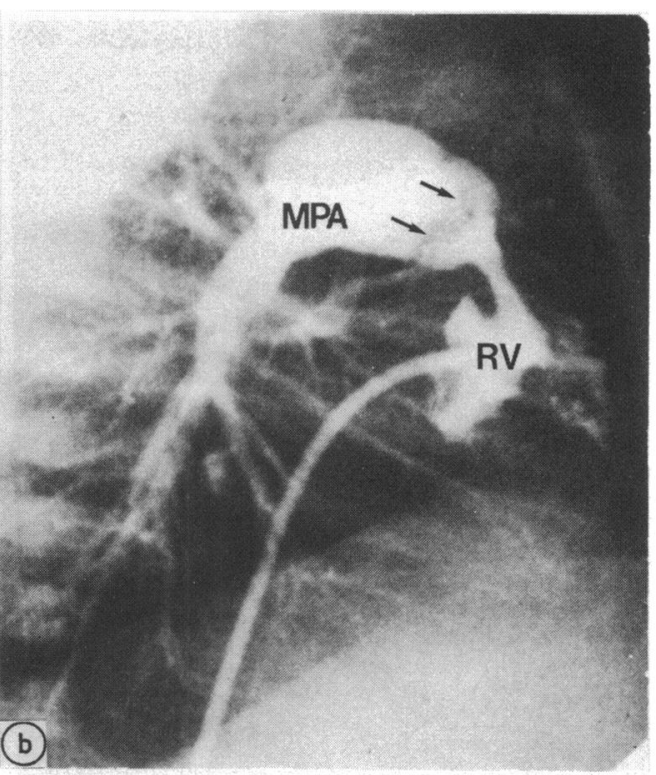

Fig. 3 (a) Anteroposterior view of selective right ventriculogram showing a hypoplastic right ventricle, narrowed infundibulum, and dilated main pulmonary artery. (b) Lateral view of the same ventriculogram showing the thick dysplastic pulmonary valve (black arrows). (c) Selective left ventriculogram outlining a large left ventricle, with contrast crossing the ventricular septal defect to outline the hypoplastic right ventricle (white arrows). $A O$, aorta; $L V$, left ventricle; $M P A$, main pulmonary artery; $R V$, right ventricle.

diagnostic method we did not use contrast echocardiography in the present study. Our results confirm the morbidity and mortality associated with cardiac catheterisation but not with echocardiography. The present study indicates that combined cross sectional echocardiography and pulsed Doppler ultrasound have a high sensitivity and specificity for detecting abnormal situs and anomalies of the atrioventricular and ventriculoarterial junctions as well as intracardiac anatomy. It was less good, however, for the identification of extracardiac vascular anomalies. This has been the experience of other investigators also ${ }^{2021}$ and is probably related to the different and tortuous routes of vessels at the base and posterior aspect of the heart. Following their courses with what is basically a tomographic technique can be difficult. Hence it is not surprising that in some babies we failed to demonstrate echocardiographically ductus arteriosus, coarctation of aorta, pulmonary artery and vein distribution, mediastinal vascular anomalies, and coronary anatomy.

In the present study the number of missed extracardiac vascular anomalies would have increased 
without pulsed Doppler ultrasound. Differences in flow patterns demonstrated by pulsed Doppler ultrasound allow venous channels to be distinguished from arteries. Persistent left superior vena cava and absent inferior vena cava with azygos continuation can be identified. The impaired blood flow distal to the site of suspected coarctation of aorta (Fig. 4), shunting across a suspected ductus arteriosus (Fig. 5), or the abnormal turbulence at the probable drainage site of isolated total anomalous pulmonary venous connection are diagnostic when these Doppler signals are present.

Pulsed Doppler ultrasound also contributes significantly to the detection of atrioventricular and ventriculoarterial junction anomalies. Atrioventricular valve regurgitation can be demonstrated readily, and subvalvar pulmonary stenosis, pulmonary valvar stenosis, and pulmonary atresia can be differentiated without difficulty. We overestimated the degree of pulmonary valvar stenosis in one baby and failed to detect the shunting across the isolated ductus arteriosus in another baby, however. The latter missed diagnosis was probably related to a high $\mathrm{PaCO}_{2}$ of $9 \mathrm{kPa}$ at the time of echocardiographic examination. This would lead to an

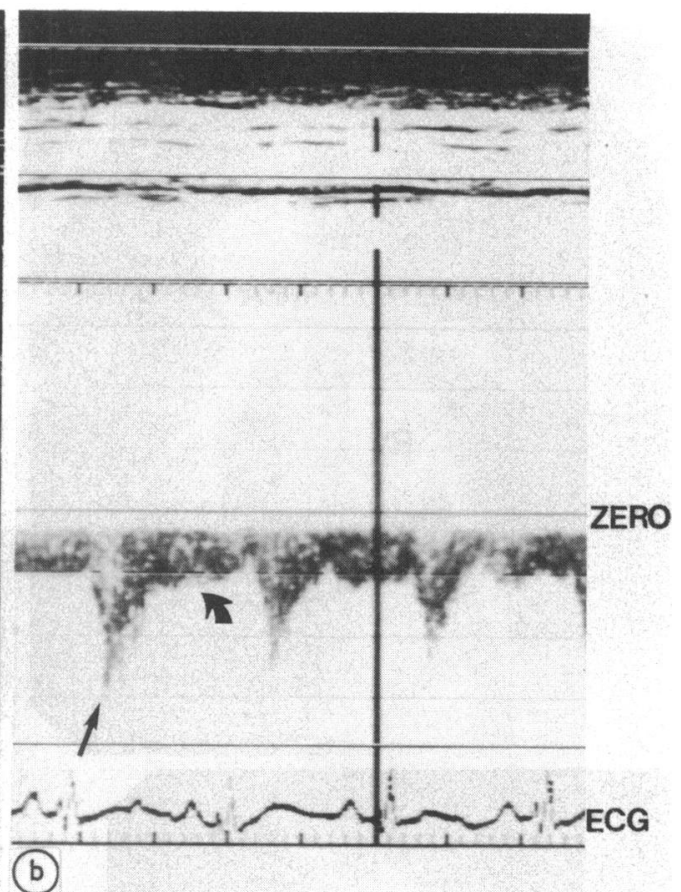

Leung, Mok, Lau, Lo, Yeung

increase in pulmonary vascular resistance and would abolish the shunting across the ductus.

We found that it was impossible to delineate with certainty the pulmonary venous connection in right $\stackrel{\mathrm{N}}{\mathrm{F}}$ isomerism associated with pulmonary atresia or $\vec{\sigma}$ stenosis. The pulmonary veins were too small to be 3 . traced and the sluggish pulmonary venous return ${ }_{0}$ precluded detection of the drainage site by pulsed $₹$ Doppler ultrasound. We also failed to identify by 0 echocardiography bilateral ductus with its associated sixth arch anomalies and sinusoidal coronary communication in pulmonary atresia and intact ventricular septum.

Although we were unable to identify some of the $N$ extracardiac vascular anomalies with echo-N cardiography, $76(79.2 \%)$ babies could have been ${ }_{0}$ correctly managed without cardiac catheterisation. The result of this study must be interpreted in the context in which it was performed, however. The $\stackrel{\circ}{+}$ physicians performing and interpreting the echo- 0 cardiograms were experienced paediatric cardiol- $\overline{0}$ ogists and echocardiographers and they were aware $\overrightarrow{\mathbb{D}}$ of the clinical findings, the results of the electro- $\frac{T}{D}$ cardiograms, and chest radiographs. Also, echo- $\frac{\varrho}{\sigma}$ cardiography was being performed with a goal- 

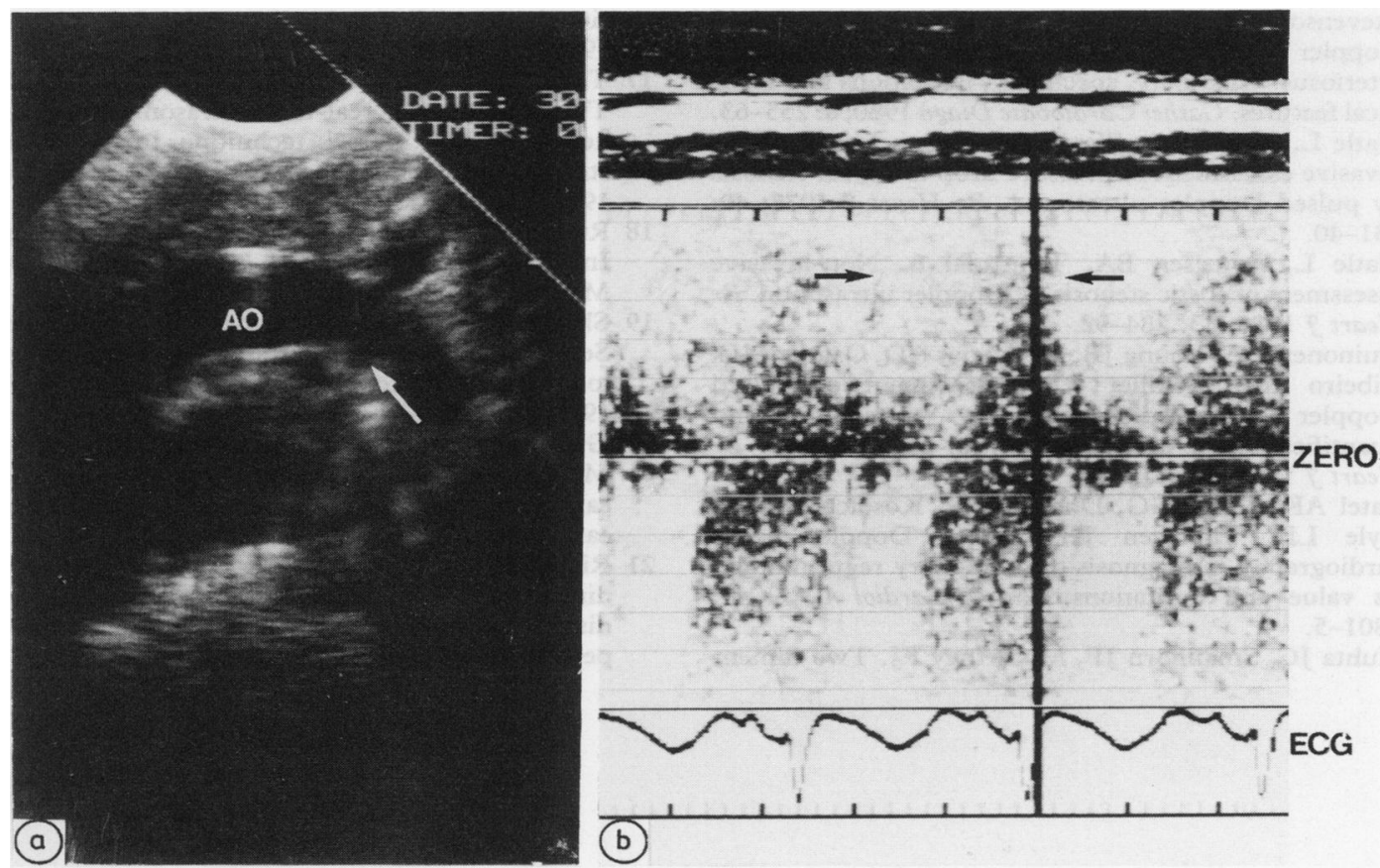

Fig. 5 (a) Cross sectional echocardiography (suprasternal view) of the aortic arch showing a ductus "diverticulum" (white arrow). The patency of the ductus was confirmed by pulsed Doppler ultrasound. (b) Graphic display of pulsed Doppler ultrasound showing the presence of turbulent flow in both systolic and diastolic phase (between black arrows). The Doppler signals below the zero line represent aliasing.

oriented approach.

Thus, in the presence of high resolution cross sectional echocardiography and pulsed Doppler ultrasound as well as expert and knowledgeable echocardiographers, few catheterisations are required in the management of neonates with suspected congenital heart disease. Clinical decisions about management may be made on the basis of echocardiography. Only a selected minority will require cardiac catheterisation and angiography.

\section{References}

1 MacMahon B, McKeown T, Record RG. The incidence and life expectation of children with congenital heart disease. $\mathrm{Br}$ Heart $\mathcal{f}$ 1953; 15: 121-9.

2 Rowe RD, Vlad P. Diagnostic problems in the newborn. Origin of mortality in congenital cardiac malformations. In: Barratt-Boyles BG, Neutz JM, Harris EA, eds. Heart disease in infancy. Diagnosis and surgical treatment. Edinburgh and London: Churchill Livingstone, 1973; 3-23.

3 Varghese PF, Celermajer J, Izukawa T, Haller JA Jr, Rowe RD. Cardiac catheterisation in the newborn: experience with 100 cases. Pediatrics 1969; 44: 24-9.

4 Sutherland GR, Godman MJ, Smallhorn JF, Guiterras
P, Anderson RH, Hunter S. Ventricular septal defects. Two dimensional echocardiographic and morphological correlations. Br Heart $\mathcal{F}$ 1982; 47: 316-28.

5 Hagler DJ, Tajik AJ, Seward JB, Mair DD, Ritter DG. Real-time wide-angle sector echocardiography: atrioventricular canal defects. Circulation 1979; 59: 140-50.

6 Rice MJ, Seward JB, Hagler DJ, Mair DD, Tajik AJ. Definitive diagnosis of truncus arteriosus by twodimensional echocardiography. Mayo Clin Proc 1982; 57: 476-8.

7 Smallhorn JF, Huhta JC, Anderson RH, Macartney FJ. Suprasternal cross sectional echocardiography in assessment of patent ductus arteriosus. $\mathrm{Br}$ Heart $\mathcal{F} 1982$; 48: $321-30$.

8 Huhta JC, Smallhorn JF, Macartney FJ, Anderson RH, de Leval M. Cross-sectional echocardiographic diagnosis of systemic venous return. Br Heart $\mathcal{F}$ 1982; 48: 388-403.

9 Smallhorn JF, Sutherland GR, Tommasini G, Hunter $\mathrm{S}$, Anderson RH, Macartney FJ. Assessment of total anomalous pulmonary venous connection by twodimensional echocardiography. Br Heart $\mathcal{f}$ 1981; 46: 613-23.

10 Stevenson JG, Kawabori I, Dooley T, Guntheroth WG. Diagnosis of ventricular septal defect by pulsed Doppler echocardiography: sensitivity, specificity and limitations. Circulation 1978; 58: 322-6. 
11 Stevenson JG, Kawabori I, Guntheroth WG. Pulsed Doppler echocardiographic diagnosis of patent ductus arteriosus: sensitivity, specificity, limitations and technical features. Cathet Cardiovasc Diagn 1980; 6: 255-63.

12 Hatle L, Brubakk A, Tromsdal A, Angelsen B. Noninvasive assessment of pressure drop in mitral stenosis by pulsed Doppler ultrasound. Br Heart $\mathcal{F} 1978$; 40: 131-40.

13 Hatle L, Angelsen BA, Tromsdal A. Non-invasive assessment of aortic stenosis by Doppler ultrasound. $\mathrm{Br}$ Heart f 1980; 43: 284-92.

14 Quinones MA, Young JB, Waggoner AD, Ostojic MC, Ribeiro LGT, Miller RR. Assessment of pulsed Doppler echocardiography in detection and quantification of aortic and mitral regurgitation. $\mathrm{Br}$ Heart If 1980; 44: 612-20.

15 Patel AK, Rowe GG, Dhanani SP, Kosolcharoen P, Lyle LE, Thomsen JH. Pulsed Doppler echocardiography in diagnosis of pulmonary regurgitation: its value and limitations. Am $\mathcal{F}$ Cardiol 1982; 49: 1801-5.

16 Huhta JC, Smallhorn JF, Macartney FJ. Two dimen- sional echocardiographic diagnosis of situs. Br Heart $\mathcal{f}$ 1982; 48: 97-108.

17 Tajik AJ, Seward JB, Hagler DJ, Mair DD, Lie JT. Two-dimensional real-time ultrasonic imaging of the heart and great vessel: technique, image, orientation, structure identification and validation. Mayo Clin Proc 1978; 53: 271-303.

18 Rudolph AM. Catheterization and angiocardiography. In: Congenital disease of the heart. Chicago: Year Book Medical Publishers, 1974: 49-50.

19 Shinebourne EA, MaCartney FJ, Anderson RH. Sequential chamber localization-the logical approach to diagnosis in congenital heart disease. $\mathrm{Br}$ Heart $\mathrm{f}$ 1976; 38: 327-40.

20 Gutgesell HP, Huhta JC, Latson LA, Huffines D, McNamara DG. Accuracy of two-dimensional echocardiography in the diagnosis of congenital heart disease. $\operatorname{Am} \mathcal{F}$ Cardiol 1985; 55: 514-18.

21 Rice MJ, Seward JB, Hagler DJ, et al. Impact of twodimensional echocardiography on the management of distressed newborns in whom cardiac disease is suspected. Am F Cardiol 1983; 51: 288-92. 